\title{
Ascitis y falla renal: no olvidar el uroperitoneo
}

\author{
Gonzalo Eymin $\mathrm{L}^{1}$, Cristián Trucco $\mathrm{B}^{2}$, Max Andresen $\mathrm{H}^{3}$. \\ Ascites and renal failure caused by a \\ bladder fistula. Report of one case
}

Bladder fistula to open peritoneum is an uncommon cause of ascites. We report a 50 year-old woman with a history of pain in the lower abdomen and slight weight loss. The patient had a history of a repaired bladder perforation 12 years before, during a labor with forceps. The patient had microscopic hematuria and an abdominal CAT scan showed ascites. Serum creatinine was $2.2 \mathrm{mg} / \mathrm{dl}$. An abdominal Doppler ultrasound showed normal portal and suprahepatic veins. Due to the suspicion that ascites accumulation could be urine, a sample was obtained and urea nitrogen and creatinine were measured. Since both levels were high in the ascitic fluid the patients was subjected to a cystoscopy that disclosed a fistula between the bladder and peritoneum. The patient was operated and the fistula excised. The postoperative period was uneventful, and the serum creatinine normalized (Rev Méd Chile 2006; 134: 345-7).

(Key-w ords: Ascites; Bladder fistula; Cystoscopy)

Recibido el 12 de abril, 2005. Aceptado el 13 de octubre, 2005.

${ }^{1}$ Departamento de Medicina Interna, ${ }^{2}$ Departamento de Urología, ${ }^{3}$ Departamento de Medicina Interna, Programa de Medicina Intensiva, Facultad de Medicina, Hospital Clínico Pontificia Universidad Católica de Chile.

$\mathrm{E}$ 1 síndrome ascítico es un problema frecuente en medicina interna. En nuestro país, la inmensa mayoría de los casos se debe a cirrosis secundaria a la ingestión de alcohol. En ausencia de cirrosis, las causas más frecuentes de ascitis son la carcinomatosis peritoneal, insuficiencia cardíaca, síndrome nefrótico y peritonitis tuberculosa. En el diagnóstico diferencial de estas patologías es de gran utilidad la punción ascítica diagnóstica y el citoquímico con recuento diferencial, que orientará a si se trata de un líquido dependiente o independiente de hipertensión portal. Sin embargo, no hay

Correspondencia a: Dr. Gonzalo Eymin L. Hospital Clínico Pontificia Universidad Católica de Chile. Marcoleta 367, Santiago, Chile. E mail: geymin@med.puc.cl que olvidar que existen otras causas menos frecuentes de ascitis, entre las que se encuentra la rotura vesical. En este sentido se presenta el caso clínico de una paciente con ruptura vesical que debutó con ascitis, leve disuria y aumento de la creatinina sérica.

\section{Caso Clínico}

Mujer de 50 años, con antecedente de hipotiroidismo en tratamiento. Un mes de evolución de dolor hipogástrico mal definido, sin disuria y con leve baja de peso. Una semana previo a su hospitalización en otro centro, el dolor se hizo intenso, tipo puntada, no irradiado, acompañado de disuria al final de la micción, sin fiebre, razón por la que se hospitalizó. 
$\mathrm{Al}$ ingreso estaba afebril, estable hemodinámicamente, con leve dolor hipogástrico. Los exámenes de ingreso mostraban un hematocrito de 46\%, 5.500 leucocitos $/ \mathrm{mm}^{3}$, sin desviación a izquierda, sedimento de orina con 4 a 6 leucocitos por campo, 40 a 45 hematíes, sin bacterias. La ecotomografía abdominal mostró líquido libre intraabdominal, lo cual fue confirmado con tomografía axial computada (TAC) de abdomen y pelvis contrastada. Se le indicó una laparotomía exploradora, por lo que la paciente decide consultar en nuestro servicio de medicina. Como antecedentes remotos tenía 2 embarazos, con un parto por cesárea y uno vaginal con forceps, 12 años antes, durante el cual sufrió una perforación vesical que fue reparada. Al ingreso destacaba una paciente en buenas condiciones generales, con leve sensibilidad en hipogastrio y con matidez desplazable, ruidos hidroaéreos normales. Exámenes de ingreso: hematocrito de 51\%, 8.000 leucocitos $/ \mathrm{mm}^{3}$ sin desviación izquierda, VHS de 6, PCR de $2,1 \mathrm{mg} /$ $\mathrm{dl}$, NU de 36 , creatinina de $2,16 \mathrm{mg} / \mathrm{dl}$, electrolitos normales, albúmina 4,3 mg/dl, colesterol $280 \mathrm{mg} / \mathrm{dl}$. Resto de perfil bioquímico y hepático normal. El sedimento de orina mostró hematíes 30 a 35 por campo, piocitos 4 a 6 por campo, regular cantidad de cocáceas y bacilos, y escasa cantidad de células del epitelio de transición. Se inició tratamiento con cefazolina $1 \mathrm{~g}$ cada $8 \mathrm{~h}$. Se realizó una paracentesis diagnóstica, que dió salida a un líquido claro, transparente, amarillento, con 10 leucocitos, $74 \%$ de mononucleares, $0,6 \mathrm{gr} / \mathrm{dl}$ de proteínas y $0,3 \mathrm{gr} / \mathrm{dl}$ de albúmina, LDH $51 \mathrm{U} / \mathrm{lt}$, glucosa $106 \mathrm{mg} / \mathrm{dl}$, colesterol $4 \mathrm{mg} / \mathrm{dl}$. Por la gradiente de albúmina se interpretó como ascitis dependiente de hipertensión portal, y ante la ausencia de patología hepática se solicitó una ecotomografía doppler de venas porta y supra-hepáticas que resultaron normales. Se dejó a la paciente en régimen de ayuno, se le instaló una sonda vesical y se aportó $3.000 \mathrm{~cm}^{3}$ de volumen intravenoso. La diuresis de 24 h fue sólo de $700 \mathrm{~cm}^{3}$ y aumentó la distensión abdominal, con incremento de $2 \mathrm{k}$ de peso. Ante la presencia de una ascitis no inflamatoria, con proteínas y albúmina muy bajas en el líquido, y habiendo descartado la hipertensión portal, en una paciente con creatinina elevada, se sospechó que la ascitis correspondiera a orina. Se realizó una paracentesis evacuante de 3 litros, con medición de nitrógeno y creatinina en el líquido, que fueron de $43 \mathrm{mg} / \mathrm{dl}$ y $10 \mathrm{mg} / \mathrm{dl}$, respectivamente. Al día siguiente no se reprodujo la ascitis y el
BUN y creatinina sérica de control fueron de $15 \mathrm{mg} / \mathrm{dl}$ y $1,09 \mathrm{mg} / \mathrm{dl}$, respectivamente. Se realizó cistoscopia que mostró una fístula vésico-peritoneal y presencia de restos de sutura en los márgenes de la fístula. Con el diagnóstico de fístula vésico-peritoneal sin causa definida, se sometió a una laparotomía exploradora, donde se evidenció moderada cantidad de líquido libre claro y transparente, órganos abdominales sanos, útero y anexos sin lesiones. Se confirmó un orificio estrellado de 1,5 centímetros de diámetro, anfractuoso, en la cúpula vesical, desde el cual fluía suero estéril a la cavidad peritoneal, al inyectarlo desde la sonda uretrovesical. No había epiplón ni asas adheridas a la vejiga. La fístula estaba en un área de pared vesical muy delgada, donde no hay detrusor, que protruía hacia la cavidad. Se resecó la zona debilitada de la vejiga hasta encontrar detrusor de aspecto sano, realizándose una cistorrafia. Se dejó drenaje peritoneal por contrabertura y se drenó la vejiga con una sonda Foley de lumen amplio (Fr. 24). Tuvo evolución postoperatoria favorable, recuperando tránsito intestinal, sin hematuria ni elementos sugerentes de infección. Se mantuvo con sonda vesical por una semana, completó tratamiento antibiótico y se controló con urocultivo negativo y biopsia que mostró una mucosa vesical sana pero adelgazada en relación al área del divertículo.

\section{DisCUSIÓN}

Estadísticas norteamericanas muestran que $80 \%$ de las ascitis se deben a cirrosis. Cuando ésta no está presente, entonces hay que considerar otras alternativas, como cáncer, insuficiencia cardíaca, tuberculosis, diálisis, pancreatitis, mixedema, lupus eritematoso, síndrome nefrótico, VIH, peritonitis por clamídea y lesión de linfáticos o de la vía urinaria. En este último caso, hay que considerar que la ruptura vesical espontánea es un cuadro muy poco frecuente en la población general, si bien hay múltiples comunicaciones en la literatura ${ }^{1-5}$. Menos frecuente aún es la ruptura vesical recurrente ${ }^{6,7}$. Las principales causas de ruptura vesical son los accidentes, y las secundarias a cirugías abdómino-pélvicas. Cuando es espontánea se presenta en general en una vejiga enferma, o bien en casos de obstrucción del tracto urinario. Entre las causas descritas destacan obstrucción del tracto urinario, divertículos, material de sutura, ingesta de grandes cantidades de alcohol, 


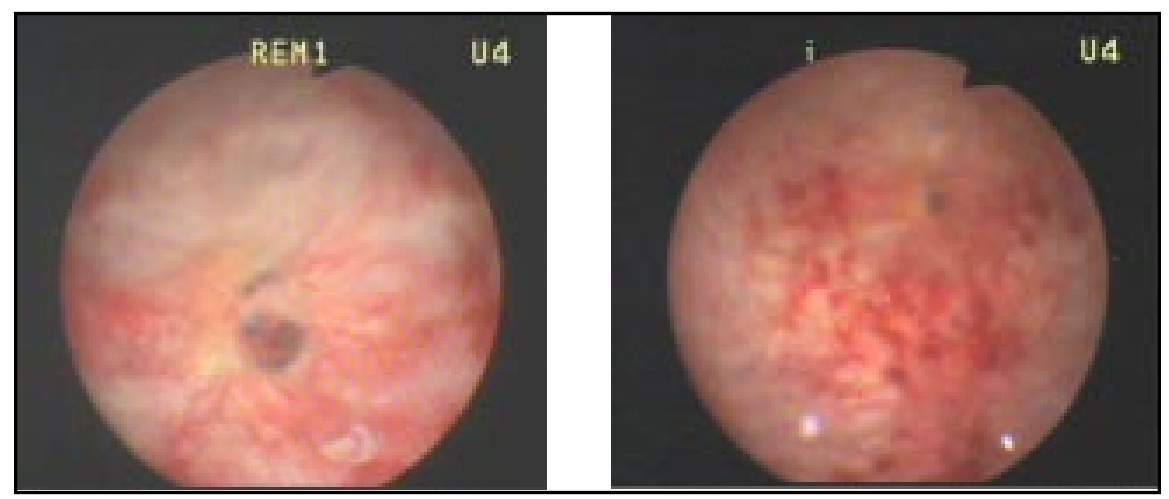

Cistoscopia que muestra orificio en la vejiga.

neoplasias, litiasis, candidiasis, tuberculosis y esquistosomiasis vesical, vejiga neurogénica y en el postparto ${ }^{1,5,8-10}$. Su forma de presentación es variable. A veces debuta como un cuadro de abdomen agudo, en cuyo caso es frecuente que el diagnóstico se haga en pabellón alcanzando una mortalidad de hasta 25\%, o bien presentarse como un cuadro de insuficiencia renal oligúrica $2,3,12-14$. En este caso el diagnóstico se sospecha por oliguria, azotemia, acidosis, la presencia de creatinina, urea y nitrógeno aumentado en el líquido peritoneal, rápida caída de la creatinina sérica y aumento del volumen urinario al drenar el líquido ascítico e instalar una sonda vesical $^{4,10}$. El aumento de la creatinina sérica estaría

\section{REFERENCIAS}

1. Shaked A, Meretyk S, Pode D, Caine M. Nontraumatic spontaneous rupture of the urinary bladder. Can J Surg 1986; 29: 107-9.

2. Juul $P$, HojHus H. Spontaneous rupture of the urinary bladder. Scand J Urol Nephrol 1985; 19: 155-6.

3. JENKINSON LR. Spontaneous intraperitoneal rupture of the urinary bladder. Postgrad Med J 1981; 57: 269-70.

4. Shumaker BP, Pontes JE, Pierce JM JR. Idiopathic rupture of the bladder. Urology 1980; 15: 566-8.

5. Agapitidis $\mathrm{N}$, Papadopollos $\mathrm{N}$, Papastamatiou L. A rare case of spontaneous rupture of the urinary bladder. South Med J 1976; 69: 244-5.

6. LAVELle MA. Recurrent spontaneous rupture of the urinary bladder. Br J Clin Pract 1990; 44: 790-2.

7. Gelister JS, Peters JL. Recurrent idiopathic bladder rupture. Eur Urol 1985; 11: 136.

8. Kibel AS, Staskin DR, Grigoriev VE. Intraperitoneal bladder rupture after normal vaginal delivery. J Urol 1995; 153 (3 pt 1): 725-7. dado por su reabsorción desde el peritoneo a la sangre, de ahí que se produzca un rápido descenso en la creatininemia al drenar el líquido y al favorecer la salida de la orina por la vejiga descomprimiendo el sistema con una sonda vesical (cuando no hay estallido, sino más bien un orificio), teniendo estos casos mejor pronóstico que los que se presentan con abdomen agudo.

Este caso es muy ilustrativo respecto a la presencia de ascitis de causa poco frecuente. Si bien no es un cuadro infrecuente de ver por los urólogos en relación a traumatismos, sí lo es para internistas, de ahí que es importante tener siempre un alto grado de sospecha.

9. Iтон N, Kounami T. Spontaneous rupture of a bladder diverticulum: ultrasonographic diagnosis. J Urol 1994; 152: 1206-7.

10. Ramcharan K, Poon-King TM, Indar R. Spontaneous intraperitoneal rupture of a neurogenic bladder, the importance of ascitic fluid urea and electrolytes in diagnosis. Postgrad Med J 1987; 63: 999-1000.

11. Schraut WH, Huffman J, Bagley DH. Acute abdominal pain caused by spontaneous perforation of the urinary bladder. Surg Gynecol Obstet 1983; 156: 589-92.

12. Basavaraj DR, Zachariah KK, Feggetter JG. Acute abdomen remember spontaneous perforation of the urinary bladder. J R Coll Surg Edinb 2001; 46: 316-7.

13. Pintar TJ, Wilke RA. Urinary ascites: spontaneous bladder rupture presenting as acute oliguric renal failure. Am J Med 1998; 105: 347-9.

14. Ratliff DA, Scoble JE. Spontaneous perforation of the bladder presenting as apparent acute renal failure. Br J Urol 1987; 60: 369. 